\title{
NUMERICAL ANALYSIS OF THE CRITICAL STATE OF THIN-WALLED STRUCTURE WITH Z-PROFILE CROSS SECTION
}

\author{
Patryk Różyło', Daniel Łukasik' \\ 1 Faculty of Mechanical Engineering, Lublin University of Technology, Nadbystrzycka 36, 20-618 Lublin, Poland, \\ e-mail: p.rozylo@pollub.pl, d.lukasik@pollub.pl
}

Received: 2016.12 .15

Accepted: 2017.02.01

Published: 2017.03.01

\begin{abstract}
The object of the study was a thin-walled profile with Z-shaped cross section made of the carbon-epoxy composite. The material model was prepared based on the implemented orthotropic properties. The purpose of the study was to determine the value of the critical load at which buckling occurs, the form of buckling and operating characteristics in critical condition. In order to achieve this numerical analysis were carried out. Additionally, the effects of the modification in arrangement of layers of the laminate to the stability and strength of thin-walled composite structures was presented. Numerical studies were carried out using commercial simulation software ABAQUS®. Within the FEM research, both forms of buckling and the associated critical load, dependent on the configuration the layers of the composite were achieved. The analysis of the obtained results allowed the evaluation of the structure's work in relation to the level of energy consumption or rigidity estimation. In the paper only numerical simulations of the critical state were conducted.
\end{abstract}

Keywords: thin-walled structures, finite element method, composites, buckling.

\section{INTRODUCTION}

Thin-walled composite structures are now one of the most desirable structures by aerospace, automotive and construction industries, due to their high strength properties while maintaining an extremely low own weight. The widespread desire to replace conventional isotropic materials with composite materials is often dictated by the harsh working conditions of construction, which enables a completely new approach to technical solutions.

Thin-walled structures belong to a group of bearing elements, characterized by a very high level of stiffness and strength. The main threats posed by the use of thin-walled structures is buckling, commonly presented in a significant number of scientific papers $[3,5 \div 7,13,16,19]$. Buckling under axial compression process involves the transition of the linear to the non-linear structure's range of work.
There is no possibility to return to the original shape of the objects in the case of exceeding the range of elasticity of a thin-walled profiles. The high level of usability of thin-walled structures is associated with the elastic nature of the work. Thus, despite further work of the structure after reaching buckling, adverse effect on the correct operation is caused by the loss of stability which has been shown in studies [5, 11, 23, 25].

Given the fact that the thin-walled composite structure is characterized by the three stages of work (pre-critical, critical and post-critical), as part of ongoing research attempts to analyze structural behavior in critical condition have been made. The state in which the loss of stability is the most complex state in the framework of work of the structure, as it is associated with the bifurcation phenomena - change in characters of work from linear to non-linear. Within the pre-critical state, the walls of the thin-walled composite structures are only compressed, but in 
post-critical - the continued growth of deflections occurs, originated from the bended walls of the profile. In the research, analysis of the critical state (associated with the loss of stability) of the composite Z-shaped cross-sectioned profile were carried out.

The idea of having thin-walled composite profiles of complex cross-section shape is to directly affect the operating conditions to provide enhancement. The issues associated with stability, critical state and low post-critical state were considered for a long time, the results of which were shown in elaborations $[3,5,9,12,16,17$, $23,25]$. The axial compression is a process commonly found in exploitations of utility construction areas, aerial construction and automotive components. The essence of the work was to show the comparative state of strength, conducted on identical models of Z-shaped profiles, taking into account only the variable configuration of the layers of the laminate. The issue of stability of the structure with varying configurations of layers in profiles with complex cross-sections is not an area which has been examined thoroughly enough. Taking the need for solutions that improve the performance of structures, provides the basis for a detailed analysis of the critical state of load-bearing composite structures. The article presents numerical study of the critical state and the impact of using different layer systems on the stability and strength of the analyzed composite thin-walled profiles with constant cross-section. As part of the conducted studies both forms of buckling with associated critical loads and performance characteristics of profiles in critical condition have been presented.

\section{SUBJECT OF RESEARCH}

The subject of the study was a thin-walled profile made of a composite carbon-epoxy composite characterized by a constant cross section. Thin-walled structure was made of unidirectional tape with regard to the carbon epoxy composite. The thickness of the single layer was $0.131 \mathrm{~mm}$, the total thickness of the specimen due to the constituent of 8 layers of the laminate was slightly more than $1 \mathrm{~mm}$. The mechanical properties of the single layer of the composite are related to the Young's modulus in the direction of fiber - $130.71 \mathrm{GPa}$ in a direction perpendicular to the fiber $6.36 \mathrm{GPa}$, the

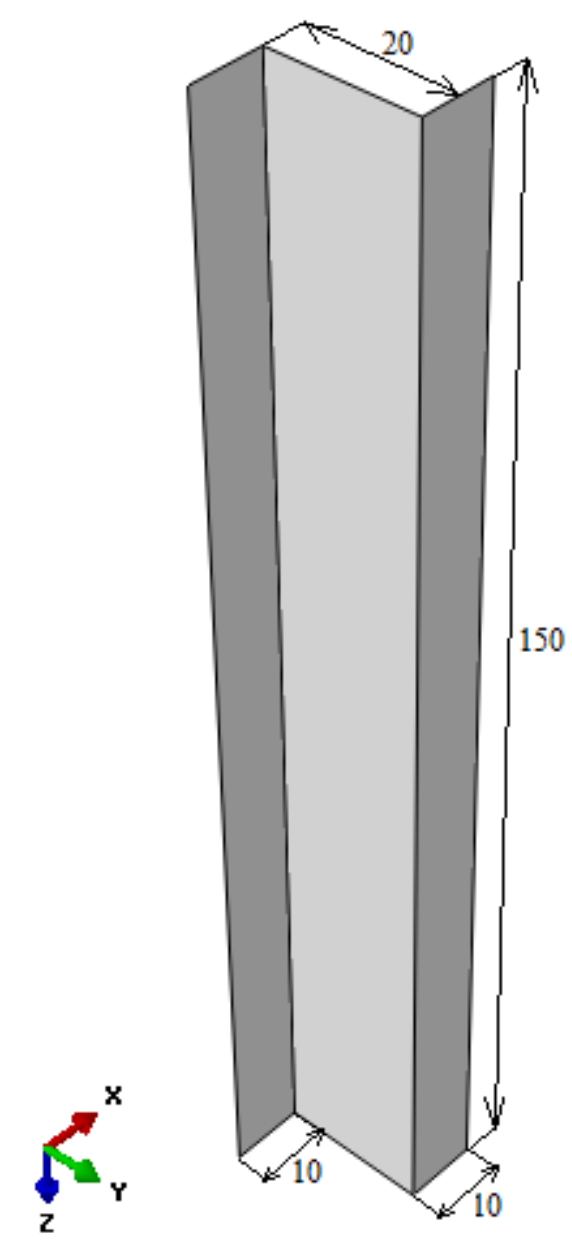

Fig. 1. Parameterized test sample

Poisson's ratio of 0.32 , the Kirchhoff's modulus of $4.18 \mathrm{GPa}$, compression strength in the direction of fiber $1.531 \mathrm{GPa}$ and perpendicular to the fiber $0214 \mathrm{GPa}$. Mechanical characteristics determined through experimental methods helped further definition of the FEM model [2]. The design of the thin-walled Z-shaped crosssection was presented in Figure 1.

The numerical model has been prepared using the FEM software - ABAQUS ${ }^{\circledR}[1]$. Variable parameters within the framework of the analyzes was only the configuration of the composite layers . Within the operation, four different cases of arrangement of layers of the laminate were examined, [0/90/0/90]s, [90/0/90/0]s, [45/$45 / 0 / 90]$ s and [90/0/-45/45]s. In the context of numerical calculations, only the first and, at the same time, the most likely to obtain a mode of buckling for each configuration of the laminate layers was determined. Numerical presentation of all the tested configurations layers alignment of the laminate were shown in Figure 2. 

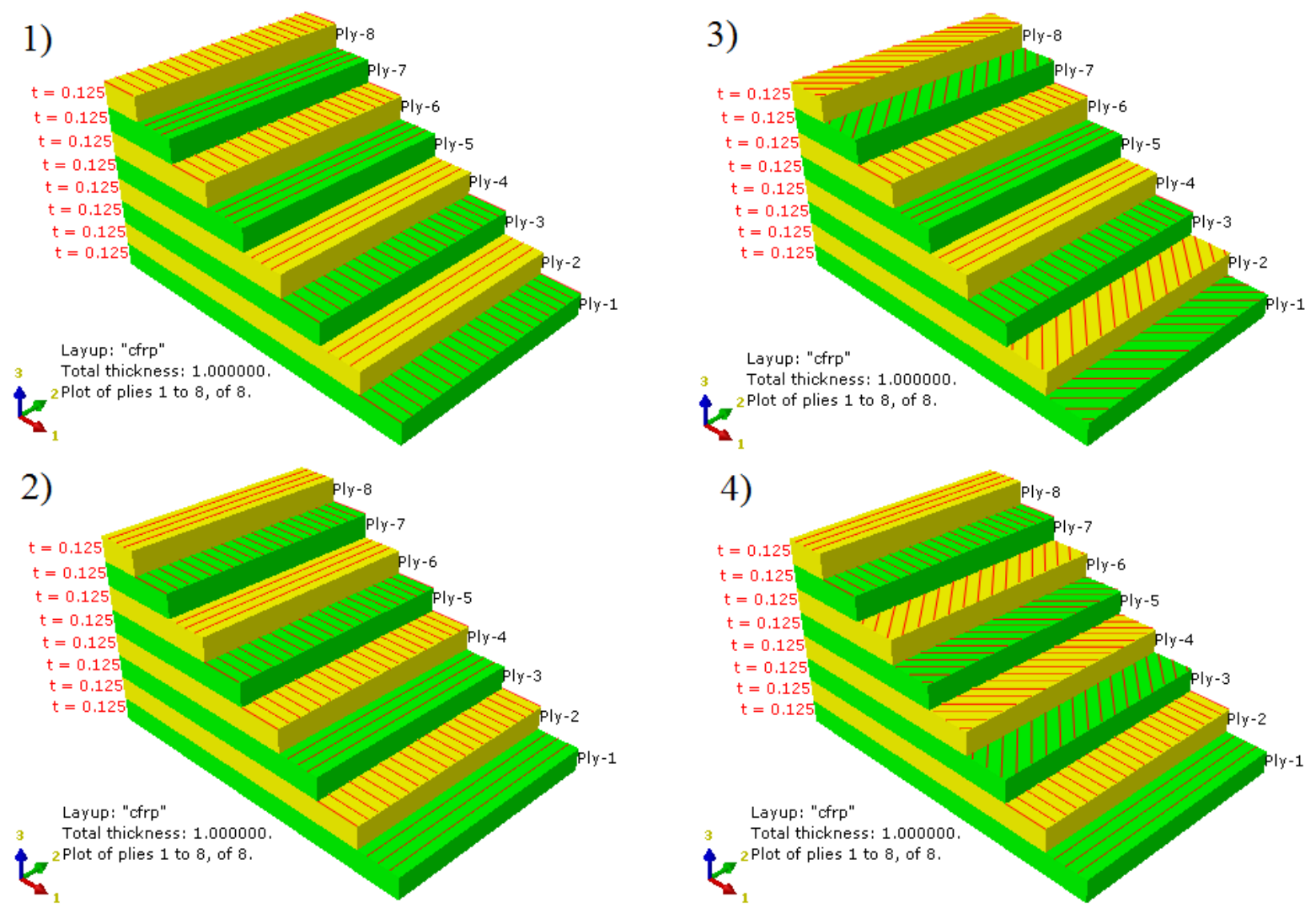

Fig. 2. Cases of the configurations of the fibers laminate: 1) $[0 / 90 / 0 / 90] s, 2)[90 / 0 / 90 / 0] s$, 3) $[45 /-45 / 0 / 90] \mathrm{s}, 4)[90 / 0 /-45 / 45] \mathrm{s}$

\section{METHODOLOGY OF THE RESEARCH}

Numerical studies were restricted to the determination of the first form of buckling, obtainable in the most accurate way to the actual experimental research. The ability of design the properties of stiffness of the thin-walled composite profiles is relevant to proper operations of structures. Due to the occurrence of complex numerical analysis in the study of stability loss, FEM calculations were carried out based on the method of NewtonRaphson, acting iterative algorithm for determining the approximate values of roots of the function describing the problem [26].

Possibility of influencing the formation of the elastic properties of composite structures is significant in order of proper handling of the objects, particularly when it is necessary to use thin-walled profiles depending specifically on the intended use. The analysis of critical state involved visualization of the first form of buckling element. The purpose of the study of critical state based on the finite element method was to determine the critical load, under which buckling occurs. The effect of changes in the layers of the laminate on the carrying capacity of thin-walled composite structures and buckling mode were studied. Boundary conditions of the models prepared for the finite element models calculations were defined considering the articulated attachment of the lower and upper edges of the profiles. The movement under load of the upper edges of the structure, was conducted uniformly over the entire length of the model together with a progressive increase in the level defined by the unitary load. The following figure (Fig. 3) shows defined boundary conditions with a unitary load in the example of the model and at the length of extrusion the profile at $150 \mathrm{~mm}$.

The load of the model had been associated with the application of the unitary force to the upper edges, in order to determine the critical force under with the buckling structure operates. The solution of eigenvalue problem in terms of the critical work of the model was associated with clearly defined process of discretization of the numerical element. The discretization process was based on the use of eight-node S8R elements, characteristic for coating models having the $6 \mathrm{de}$ - 


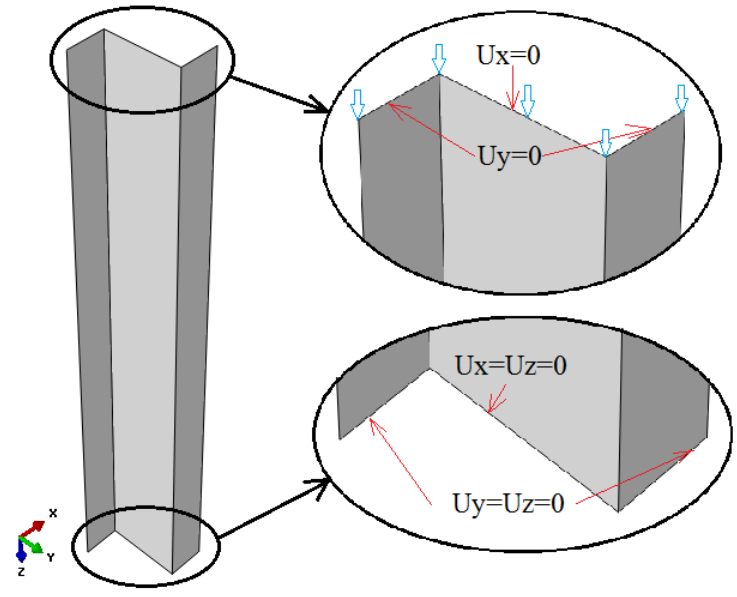

Fig. 3. The boundary conditions of the numerical model

grees of freedom in the nodes, with reduced integration, which are described by the squared function of shape. The reduced integration technique is associated with the removal of false forms of the

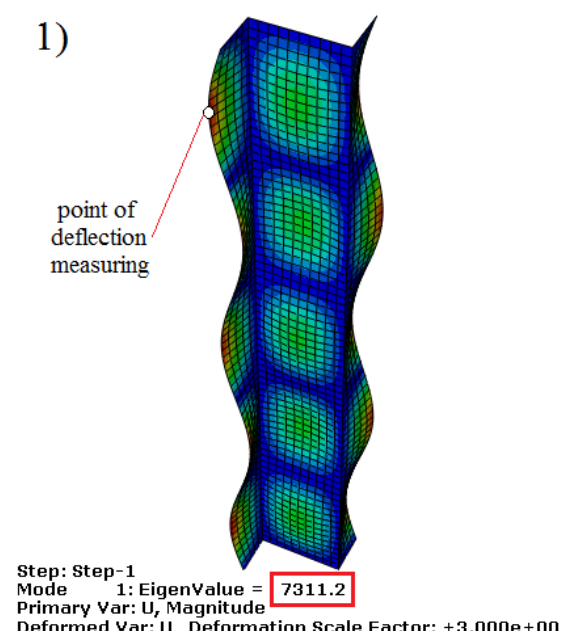

Deformed Var: U Deformation Scale Factor: $+3.000 e+00$

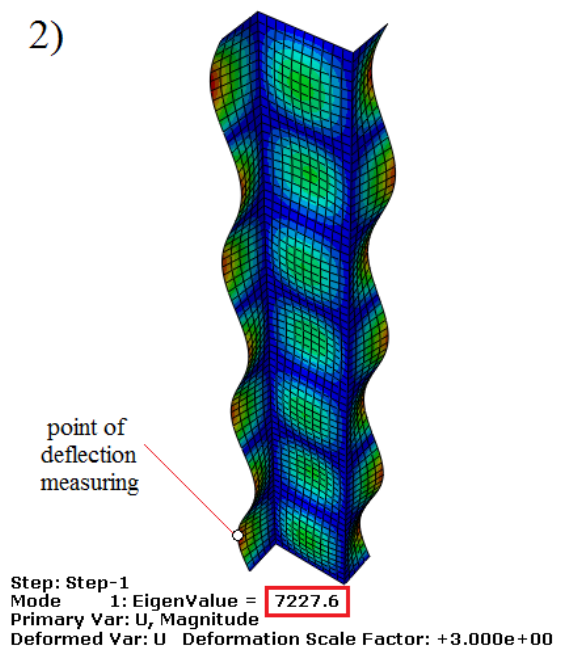

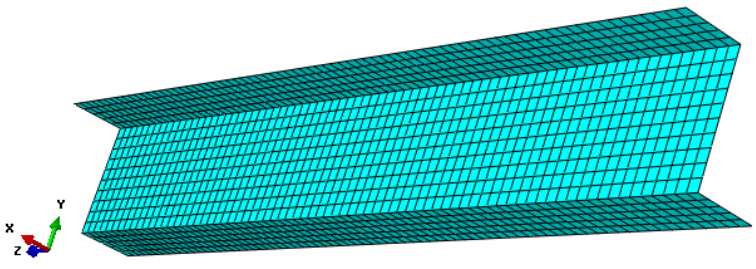

Fig. 4. Discrete model of the thin-walled composite structure

deformation occurring in the calculation of higher order polynomial, in order to obtain average of correct results, under the condition of the stressdisplacement occurring at nodes [26]. The following figure (Fig. 4) shows the form of the generated finite element mesh in the tested structure.

For the conducted discretization of the numerical model, 1500 mesh elements with 4691 nodes was obtained. On the basis of the properly prepared numerical models initial FEM analysis was

3)

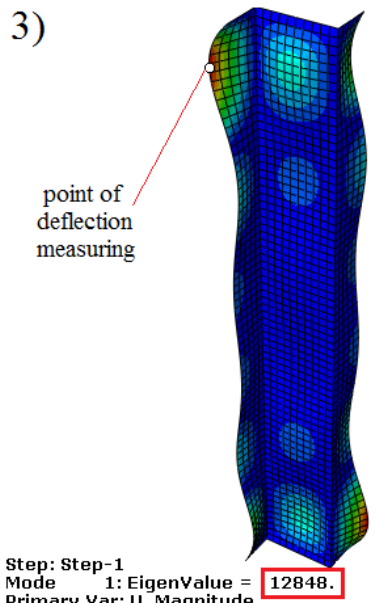

Primary Var: U, Magnitude

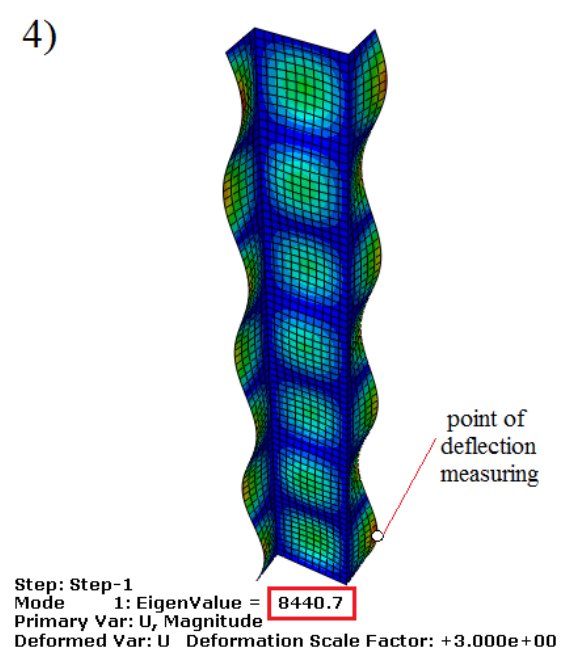

Fig. 5. Visualization of the first form of buckling: 1) profile configuration [0/90/0/90]s, 2) profile configuration $[90 / 0 / 90 / 0] \mathrm{s}, 3)$ profile configuration $[45 /-45 / 0 / 90] \mathrm{s}, 4)$, the profile configuration $[90 / 0 /-45 / 45] \mathrm{s}$ 
Table 1. Summary of the results of numerical calculations for each layer configuration

\begin{tabular}{|c|c|c|c|c|}
\hline & {$[0 / 90 / 0 / 90] s$} & {$[90 / 0 / 90 / 0] s$} & {$[45 /-45 / 0 / 90] s$} & {$[90 / 0 /-45 / 45] s$} \\
\hline Half-waves & 5 & 7 & 6 & 7 \\
\hline Critical force & $7311,2[\mathrm{~N}]$ & $7227,6[\mathrm{~N}]$ & $12848[\mathrm{~N}]$ & $8440,7[\mathrm{~N}]$ \\
\hline
\end{tabular}

conducted in order to obtain the critical conditions from buckling, for each configuration of the fibers. The next stage was to determine the critical force within the studied numerical models.

\section{THE RESULTS OF NUMERICAL ANALYSIS}

On the basis of the properly defined aspects of buckling process, first forms of loss of stability occurring in composite structures were presented. The value of critical forces and the points of measurement of profile's deflection, depending on the configuration of the layers of the laminate were shown in Figure 5.

Based on the combined results, it is evident that the buckling mode varies depending on configuration of layers alignment. An additional result followed directly from the analysis was the critical force obtain for each case. Critical forces are the most important parameter possible to obtain in the context of the critical state of thin-walled structures. A higher level of critical load indicates higher stiffness characteristics of the structure, while the lower level enhanced energy-intensive properties. The following table (Table 1) summarizes the results of critical loads and the number of half-waves adequate for each of the used configuration of arrangement of the layers of the laminate.

\section{CONCLUSIONS}

The paper presented the issues of stability of the working thin-walled profiles subjected to axial compression. The study based on the finite element method showed the impact of changes in configuration of layers in the laminate on critical force and buckling forms of the structure. The level of increased performance and reliability of thin-walled structures is possible by the control of the layer system. Depending on the requirements, there is the ability to design the properties of the thin-walled composite structure so that they are more rigid and energy-intensive.

Based on the study the following conclusions were formed:

1. The change in configuration alignment in layers of the laminate has an impact on critical loads and the mode of buckling.

2. Via the variable configuration of the fiber in laminate, it is possible to obtain operating characteristics corresponding to the stiffer or more energy-absorbing structures.

\section{Equilibrium paths}

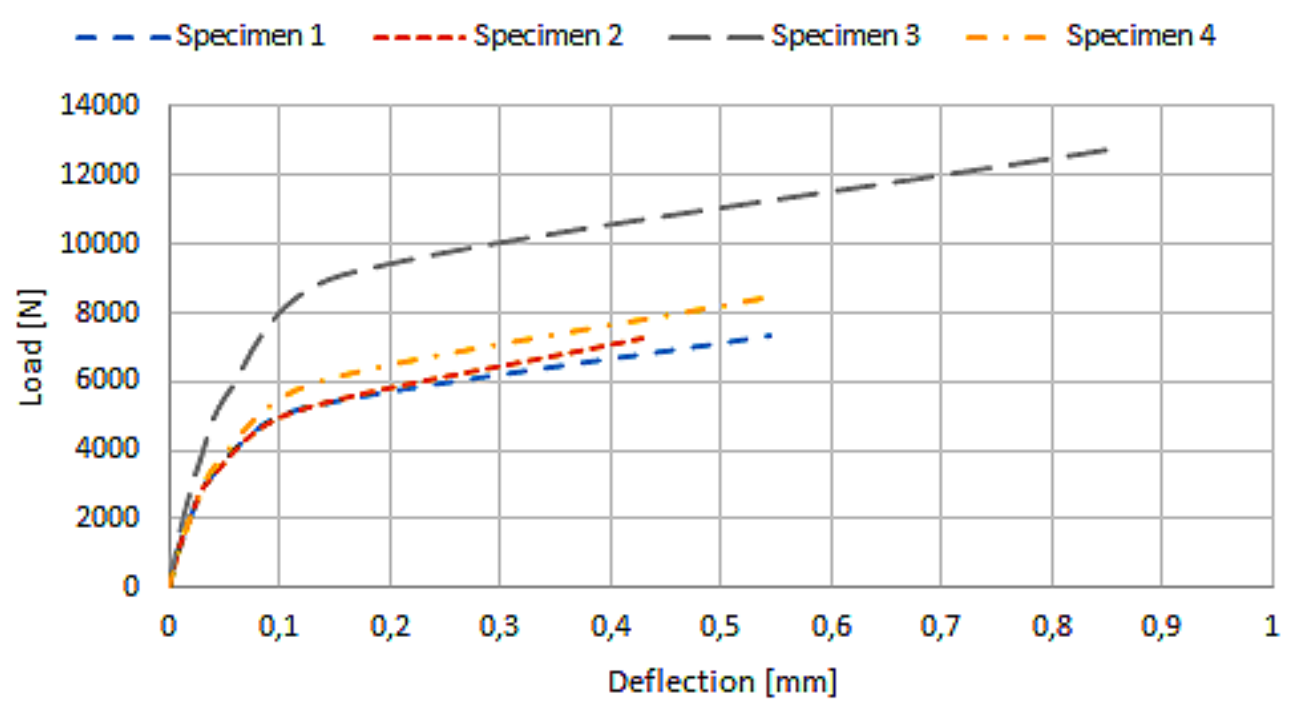

Fig. 6. Equilibrium paths of the tested profiles 
3. Buckling mode obtained in the study takes the same form of deformation for profiles of different heights.

4. The course of equilibrium paths in critical states determines the state of load-bearing capacity of structures.

The obtained FEM results show possibilities of in-depth study of deformation states and assessment of the correct operation range of thinwalled profiles in terms of the critical load. Numerical analysis based on advanced simulation software, are a powerful tool enabling the study of the state of load capacity and material effort occurring in thin-walled structures under the influence of properly defined boundary conditions. Further research will be related to the assessment of structures in post-critical state and determination of potential areas of destruction under the influence of overloads affecting the structures.

\section{REFERENCES}

1. Abaqus HTML Documentation.

2. Dębski H.: Badania numeryczne i doświadczalne stateczności i nośności kompozytowych słupów cienkościennych poddanych ściskaniu. Zeszyty naukowe nr 1161, Wydawnictwo Politechniki Łódzkiej, Łódź, 2013.

3. Dębski H.: Experimental investigation post-buckling behaviour of composite column with top-hat cross section. Eksploatacja i Niezawodnosc Maintenance and Reliability (2013); 2: 106-110.

4. Dębski H, Koszałka G, Ferdynus M.: Application of fem in the analysis of the structure of a trailer supporting frame with variable operation parameters. Eksploatacja i Niezawodnosc - Maintenance and Reliability (2012); 14 (2): 107-114.

5. Dębski H., Teter A., Kubiak T., Samborski S.: Local buckling, post-buckling and collapse of thin-walled channel section composite columns subjected to quasi-static compression. Composite Structures (2016); 136: 593-601.

6. Falkowicz K., Ferdynus M., Dębski H.: Numerical analysis of compressed plates with a cut-out operating in the geometrically nonlinear range. Eksploatacja i Niezawodność - Maintenance and Reliability (2015); 17(2): 222-227.

7. Falkowicz K., Mazurek P., Rozylo P., Wysmulski P., Smagowski P.: Experimental and numerical analysis of the compression of a thin-walled composite plate. Advances in Science and Technology, Research Journal (2016); 10(31): 177-184.

8. Ferdynus M.: An energy absorber in the form of a thin-walled column with square cross-section and dimples. Eksploatacja i Niezawodność - Maintenance and Reliability (2013); 15(3): 253-258.

9. Koiter W.T.: Elastic stability and post-buckling behavior. In Proceedings of the Symposium on Nonlinear Problems. Wisconsin: Univ. of Wisconsin Press (1963); 257- 275.

10. Kołakowski Z., Teter A.: Load carrying capacity of functionally graded columns with open cross-sections under static compression. Composite Structures (2015); 129: 1-7.

11. Kopecki T., Mazurek P.: Numerical representation of post-critical deformations in the processes of determining stress distributions in closed multi-segment thin-walled aircraft load-bearing structures. Eksploatacja i Niezawodnosc - Maintenance and Reliability (2014); 16(1): 164-169.

12. Kopecki T., Mazurek P.: Problems of numerical bifurcation reproducing in postcritical deformation states of aircraft structures. Journal of Theoretical and Applied Mechanics (2013); 51(4): 969-977.

13. Królak M. and Mania R.J.: Statics, dynamics and stability of structures. Stability of thin-walled plate structures. Series of monographs. Lodz: Technical University of Lodz, (2011).

14. Lonkwic P., Rozylo P.: Theoretical and experimental analysis of loading impact from the progressive gear on the lift braking distance with the use of the free fall method. Advances in Science and Technology Research Journal, 10 (30), 2016, 103-109.

15. Lonkwic P., Rozylo P., Dębski H.: Numerical and experimental analysis of the progressive gear body with the use of finite-element method. Eksploatacja i Niezawodnosc - Maintenance and Reliability (2015); 17(4): 544-550.

16. Mania R.J., Kołakowski Z., Bienias J., Jakubczak P., Majerski K.: Comparative study of FML profiles buckling and post-buckling behavior under axial loading. Composite Structures (2015); 134: 216-225.

17. Ritchie D., Rhodes J.: Buckling and post-buckling behaviour of plates with holes. The Aeronautical Quarterly (1975); 26(4): 281-296.

18. Rozylo P.: Optimization of I-section profile design by the finite element method. Advances in Science and Technology, Research Journal, 10 (29), 2016, 52-56.

19. Rozylo P., Wrzesinska K.: Numerical analysis of the behavior of compressed thin-walled elements with holes. Advances in Science and Technology, Research Journal (2016); 10(31): 199-206.

20. Rudawska A., Debski H., Experimental and numerical analysis of adhesively bonded aluminium alloy sheets joints. Maintenance and Reliability, 1, 2011, 4-10.

21. Samborski S.: Numerical analysis of the DCB test configuration applicability to mechanically coupled Fiber Reinforced Laminated Composite beams. 
Composite Structures (2016), 152, 477-487.

22. Shanmugam N.E.: Openings in Thin-walled Steel Structures. Thin-Walled Structures (1997); 28(3/4): 355-372.

23. Teter A., Dębski H., Samborski S.: On buckling collapse and failure analysis of thin-walled composite lipped-channel columns subjected to uniaxial compression. Thin-Walled Structures (2014); 85: 324-331.
24. Thompson J.M.T., Hunt G.W.: General theory of elastic stability. New York: Wiley, 1973.

25. Wysmulski P., Dębski H., Rozylo P., Falkowicz K.: A study of stability and post-critical behaviour of thin-walled composite profiles under compression. Eksploatacja i Niezawodnosc - Maintenance and Reliability, 18 (4), 2016, 632-637.

26. Zienkiewicz O.C., Taylor R.L.: Finite Element Method, 5th Ed., Vol. 2 - Solid Mechanics. Elsevier, 2000. 